\title{
Nuclear Expression of Phosphorylated EGFR Is Associated with Poor Prognosis of Patients with Esophageal Squamous Cell Carcinoma
}

\author{
Mina Hoshino ${ }^{a}$ b Hirokazu Fukui ${ }^{a}$ Yuko Ono $^{a}$ Akira Sekikawa $^{a}$ \\ Kazuhito Ichikawa ${ }^{a}$ Shigeki Tomita ${ }^{a}$ Yasuo Imai ${ }^{a}$ Johji Imura ${ }^{a}$ \\ Hideyuki Hiraishi $^{\mathrm{b}}$ Takahiro Fujimori ${ }^{\mathrm{a}}$ \\ Departments of a Surgical and Molecular Pathology and ${ }^{b}$ Gastroenterology, Dokkyo University School of Medicine, \\ Tochigi, Japan
}

\section{Key Words}

Esophagus $\cdot$ Squamous cell carcinoma $\cdot$ Epidermal growth factor receptor $\cdot$ Phosphorylation $\cdot$ Prognosis

\begin{abstract}
Objectives: Although it has been reported that epidermal growth factor receptor (EGFR) is able to translocate from the plasma membrane to the nucleus, the pathophysiological role of this translocation in tumorigenicity is still unclear. In the present study, to elucidate the pathophysiological significance of EGFR translocation, we investigated the expression not only of conventional EGFR but also its phosphorylated form (pEGFR), focusing on its cellular localization in esophageal cancer tissues. Methods: Fifty-two specimens of esophageal squamous cell carcinoma (SCC) obtained by surgery were examined immunohistochemically for their EGFR and pEGFR immunostaining patterns. The relationships between clinicopathological parameters and EGFR or pEGFR immunostaining patterns were then analyzed. Results: In 37 (71.2\%) of the 52 esophageal SCCs, EGFR immunoreactivity was clearly localized at the plasma membrane of the cancer cells, whereas pEGFR immunoreactivity was clearly localized in the nucleus in 19 (36.5\%) cases. Nuclear expression of pEGFR significantly correlated with TNM stage and lymph node metastasis, and moreover was associated with a poor outcome of esophageal SCC. Conclusions: Nuclear translo-
\end{abstract}

calization of pEGFR is associated with an increase in the malignant potential of esophageal SCC and may affect prognosis in patients with esophageal SCC.

Copyright $\odot 2007$ S. Karger AG, Basel

\section{Introduction}

Epidermal growth factor receptor (EGFR), a single transmembrane glycoprotein, possesses intrinsic tyrosine kinase activity [1] and transmits extracellular information to the nucleus via an intracellular signaling network following its autophosphorylation [2,3]. In normal tissues, EGFR signaling is finely tuned for the precise control of cell proliferation, whereas in tumor tissues it is frequently dysregulated, thus contributing to the disordered proliferation of tumor cells $[4,5]$. EGFR overexpression has been identified as a common feature of many types of cancer, and its association with clinical outcome in patients with malignant diseases has been studied because of the roles of EGFR signaling not only in cell proliferation but also antiapoptosis, metastasis and angiogenesis [6]. Indeed, several immunohistochemical studies have revealed that EGFR overexpression is a strong prognostic marker for patients with esophageal [7] or head and neck cancer [8], and furthermore a modest one for patients with breast [9], colorectal [10] or gastric can-

\section{KARGER}

Fax +4161306 1234

E-Mail karger@karger.ch

www.karger.com
(C) 2007 S. Karger AG, Basel

1015-2008/07/0741-0015\$23.50/0

Accessible online at:

www.karger.com/pat
Takahiro Fujimori, MD, PhD

Department of Surgical and Molecular Pathology

Dokkyo University School of Medicine, 880, Kitakobayashi, Mibu, Shimotsuga Tochigi 321-0293 (Japan)

Tel. +81 28287 2130, Fax +81 28286 1681, E-Mail t-fuji@dokkyomed.ac.jp 
Table 1. Relationship between clinicopathological factors and EGFR or pEGFR expression in esophageal SCC

\begin{tabular}{|c|c|c|c|c|c|c|c|}
\hline & & \multicolumn{3}{|l|}{ EGFR } & \multicolumn{3}{|l|}{ pEGFR } \\
\hline & & $\begin{array}{l}\text { membrane } \\
(\mathrm{n}=37)\end{array}$ & $\begin{array}{l}\text { nonmembrane } \\
(\mathrm{n}=15)\end{array}$ & $\begin{array}{l}\mathrm{p} \\
\text { value }\end{array}$ & $\begin{array}{l}\text { nuclear } \\
(n=19)\end{array}$ & $\begin{array}{l}\text { nonnuclear } \\
(\mathrm{n}=33)\end{array}$ & $\begin{array}{l}\mathrm{p} \\
\text { value }\end{array}$ \\
\hline \multirow[t]{2}{*}{ Gender } & M & 28 & 14 & \multirow{2}{*}{ NS } & 16 & 26 & \multirow{2}{*}{ NS } \\
\hline & $\mathrm{F}$ & 9 & 1 & & 3 & 7 & \\
\hline Age, years & & $65.3 \pm 1.3$ & $65.5 \pm 2.6$ & NS & $65.3 \pm 2.0$ & $65.4 \pm 1.4$ & NS \\
\hline \multirow[t]{2}{*}{ Stage } & I and II & 29 & 8 & \multirow{2}{*}{0.071} & 9 & 28 & \multirow{2}{*}{0.004} \\
\hline & III and IV & 8 & 7 & & 10 & 5 & \\
\hline \multirow[t]{2}{*}{ Ly } & $(-)$ & 15 & 6 & \multirow{2}{*}{ NS } & 7 & 14 & \multirow{2}{*}{ NS } \\
\hline & $(+)$ & 22 & 9 & & 12 & 19 & \\
\hline \multirow[t]{2}{*}{$\mathrm{V}$} & $(-)$ & 21 & 9 & \multirow{2}{*}{ NS } & 9 & 21 & \multirow{2}{*}{ NS } \\
\hline & $(+)$ & 16 & 6 & & 10 & 12 & \\
\hline \multirow[t]{2}{*}{$\mathrm{N}$} & $(-)$ & 25 & 7 & \multirow{2}{*}{ NS } & 7 & 25 & \multirow{2}{*}{0.006} \\
\hline & $(+)$ & 12 & 8 & & 12 & 8 & \\
\hline \multirow[t]{2}{*}{ Histology } & Well/moderate & 23 & 8 & \multirow{2}{*}{ NS } & 8 & 23 & \multirow{2}{*}{0.051} \\
\hline & Poor & 14 & 7 & & 11 & 10 & \\
\hline
\end{tabular}
SE.

Ly = Lymphatic invasion; $\mathrm{V}=$ venous invasion; $\mathrm{N}=$ lymph node metastasis. Age was expressed as means \pm

cer [11]. However, although such studies have addressed the total level of EGFR expression, the cellular localization of either total EGFR or phosphorylated EGFR (pEGFR; the active form of EGFR) expression has not been fully examined.

Although EGFR expression is detectable at the plasma membrane immunohistochemically, it is also reportedly detectable in the nucleus in various types of cancer cells [3]. Recently, accumulated evidence has begun to suggest that EGFR may be capable of translocating from the plasma membrane to the nucleus [12], and that this translocation may play a pathophysiological role in tumorigenicity. Therefore in the present study, to elucidate the pathophysiological significance of EGFR translocation, we investigated the expression not only of total EGFR but also pEGFR, focusing on its cellular localization in esophageal cancer tissues.

\section{Patients and Methods}

Tissue Samples and Patients

Fifty-two patients with esophageal squamous cell carcinoma (SCC; 42 males, 10 females; mean age $65.4 \pm 1.1$ years, range 50-84 years) who underwent surgery at the Dokkyo University School of Medicine from 1987 to 2002 were enrolled. Patients with other malignant diseases were excluded, as were patients who had received preoperative treatment such as chemotherapy and radiation therapy. The pathologic staging was determined for each specimen according to the TNM classification of esophageal can- cer [13]. This study was done with the approval of the Dokkyo University Surgical Pathology Committee. The clinicopathological features of the patients are summarized in table 1 .

\section{Immunohistochemistry}

The surgically resected specimens were fixed in $10 \%$ neutral buffered formalin and embedded in paraffin. Immunohistochemical staining was performed as described previously [14]. In brief, $4-\mu \mathrm{m}$-thick sections were placed on slides, deparaffinized and dehydrated. They were then placed in $0.01 \mathrm{~mol} / \mathrm{l}$ citrate buffer ( $\mathrm{pH}$ 6.0) and treated by microwave heating (MI-77; Azumaya, Tokyo, Japan) at $400 \mathrm{~W}$ and $95^{\circ} \mathrm{C}$ for $10 \mathrm{~min}$ to facilitate antigen retrieval, followed by pretreatment with $0.3 \%$ $\mathrm{H}_{2} \mathrm{O}_{2}$ in methanol for $20 \mathrm{~min}$ at room temperature to quench endogenous peroxidase activity. The sections were then allowed to immunoreact using an Ultra Tech kit (Immunotech, Marseille, France) in accordance with the supplied protocols. The sections were incubated with $1 \%$ bovine serum albumin in phosphate-buffered saline (PBS) for $30 \mathrm{~min}$, and then with antiEGFR antibody (clone 31G7; Upstate Biotechnology, Lake Placid, N.Y., USA; 1:30) and anti-pEGFR antibody Tyr845 (Cell Signaling Technology, Danvers, Mass., USA; 1:50) for $1 \mathrm{~h}$. Thereafter, the sections were incubated with biotinylated secondary antibody for $15 \mathrm{~min}$, washed with PBS and treated with peroxidase-conjugated streptavidin for $20 \mathrm{~min}$. Finally, the sections were incubated in 3,3' -diaminobenzidine tetrahydrochloride with $0.05 \% \mathrm{H}_{2} \mathrm{O}_{2}$ for $3 \mathrm{~min}$ and then counterstained with Carazzi's hematoxylin.

\section{Evaluation of EGFR and pEGFR Expression}

We assessed the immunoreactivity of EGFR and pEGFR in the invasive front of esophageal squamous cell carcinoma (magnification $\times 200)$. 
As described in the Results section, some esophageal SCCs showed clear EGFR immunoreactivity at the plasma membrane (membrane type), while others showed diffuse immunoreactivity in the cytoplasm and nucleus but not at the plasma membrane (nonmembrane type). Every lesion was classified as either membrane or nonmembrane type according to its dominant immunostaining pattern.

With regard to pEGFR, some esophageal SCCs showed clear immunoreactivity in the nucleus and a weak signal in the cytoplasm and at the plasma membrane (nuclear type), whereas others showed no nuclear immunoreactivity but a diffuse signal in the cytoplasm and at the plasma membrane (nonnuclear type). Every lesion was classified as either nuclear or nonnuclear type according to its dominant immunostaining pattern.

\section{Western Blot Analysis}

A human esophageal SCC cell line, T.Tn, was maintained in a 1:1 mixture of Dulbecco's modified medium (Nissui, Tokyo, Japan) and F-12 (Life Technologies Inc., Gaithersburg, Md., USA) supplemented with $10 \%$ fetal calf serum (Sigma, St. Louis, Mo. USA) [15]. Proteins were extracted from T.Tn cells and separated to the nuclear and membrane-cytoplasmic fractions as previously described [16]. In brief, the cells were mixed with lysis buffer containing $10 \mathrm{mM}$ Tris- $\mathrm{HCl}$ (pH 7.9), $10 \mathrm{mM} \mathrm{KCl}, 1.5 \mathrm{mM} \mathrm{MgCl}_{2}$, $1 \mathrm{~mm}$ DTT, $1 \%$ Nonidet $\mathrm{P}-40$ and $1 \times$ proteinase inhibitor (Complete Mini; Roche). Proteins from membrane and cytoplasm were extracted from the supernatants and the precipitation was additionally treated with nuclear lysis buffer containing $20 \mathrm{mM}$ Tris$\mathrm{HCl}$ (pH 7.9), $400 \mathrm{~mm} \mathrm{NaCl}, 1.5 \mathrm{~mm} \mathrm{MgCl}$, $0.2 \mathrm{~mm}$ EDTA, $1 \mathrm{~mm}$ DTT, $5 \%$ glycerol and $1 \times$ proteinase inhibitor (Complete Mini; Roche). After centrifugation, nuclear protein was extracted from the treated supernatants.

Western blot analysis was carried out as previously described [17]. Briefly, protein extract $(12.5 \mu \mathrm{g})$ was fractionated by sodium dodecyl sulfate polyacrylamide gel electrophoresis and transferred to a polyvinylidene difluoride membrane. The membrane was incubated with primary antibodies and then with a peroxidase-conjugated secondary antibody. Proteins were detected using an enhanced chemiluminescence system (Amersham Pharmacia Biotech, Buckinghamshire, England).

Statistical Analysis

Statview 5.0J statistical software (Abacus Concepts Inc., Berkeley, Calif., USA) was used for all analyses. Overall survival rate was calculated by using the Kaplan-Meier method and analyzed by the log-rank test. $\chi^{2}$ analyses were performed to investigate the relationship between conventional EGFR and pEGFR expression. Differences at $\mathrm{p}<0.05$ were considered to be statistically significant.

\section{Results}

Expression of EGFR and pEGFR in Esophageal SCC

Representative immunostaining patterns of EGFR and pEGFR are shown in figure 1. In 37 (71.2\%) of the 52 esophageal SCCs, EGFR immunoreactivity was clearly localized at the plasma membrane of cancer cells (fig. 1a), and in the remaining 15 cases $(28.8 \%)$ it was detected diffusely in the cytoplasm (fig. 1b; table 1). pEGFR immunoreactivity was clearly localized in the nucleus (fig. 1c) and diffusely in the cytoplasm (fig. 1d) of cancer cells in $19(36.5 \%)$ and $33(63.5 \%)$ of the esophageal SCCs, respectively (table 1).

Localizations of EGFR and pEGFR were also examined using the esophageal SCC cell line (fig. 2). Western blots showed that EGFR was strongly expressed in the fraction of the membrane and cytoplasm, and also faintly in the fraction of the nucleus of esophageal SCC cells. The expression of pEGFR was detected in the fraction not only of the membrane and cytoplasm but also the nucleus. These findings, together with immunohistochemistry, support the specificity of pEGFR immunoreactivity in the nuclei of esophageal SCC cells.

\section{Relationship between Clinicopathological Factors and} EGFR or pEGFR Expression in Esophageal SCC

A membrane-type EGFR immunostaining pattern tended to be detected in early-stage esophageal SCCs $(p=0.071)$. However, none of the clinicopathological factors, including gender, age, histology, lymphatic invasion, venous invasion or lymph node metastasis, were significantly related to the EGFR immunostaining pattern (table 1).

A significant proportion of advanced-stage esophageal SCCs showed a nuclear pEGFR immunostaining pattern $(\mathrm{p}=0.004)$. In addition, a higher proportion of SCCs showed a nuclear pEGFR staining pattern in patients with lymph node metastasis $(60.0 \%)$ than in those without $(21.9 \%)$. In contrast, none of the remaining parameters - gender, age, histology, lymphatic invasion or venous invasion - had a significant relationship to the pEGFR immunostaining pattern (table 1).

\section{Relationship between EGFR and pEGFR \\ Immunostaining Patterns in Esophageal SCC}

We next investigated the relationships between EGFR and pEGFR immunostaining patterns because, as shown in figure 3, we often observed that cancer cells showing a nonmembrane-type EGFR immunostaining pattern expressed nuclear immunoreactivity for pEGFR. It was noteworthy that SCC specimens showing a nonmembrane-type EGFR immunostaining pattern had a significantly higher incidence of nuclear pEGFR immunostaining, whereas those showing a membrane-type EGFR immunostaining pattern had a significantly higher incidence of nonnuclear pEGFR immunostaining $(\mathrm{p}=0.0005$; table 2). 
Fig. 1. Immunostaining patterns of EGFR (a and b) and pEGFR (c and d) in esophageal SCC. a Membrane type: immunoreactivity of EGFR is clearly detected at the plasma membrane of cancer cells. b Nonmembrane type: immunostaining signal is diffusely positive in the cytoplasm but obvious at the membrane. c Nuclear type: immunoreactivity of pEGFR is clearly detected in the nuclei of cancer cells. d Nonnuclear type: immunostaining signal is diffusely positive in the cytoplasm but obvious in the nuclei.

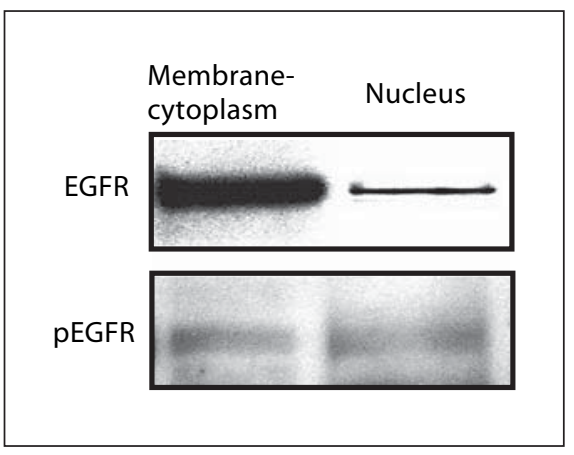

Fig. 2. Immunoreactivity of EGFR and pEGFR for membrane-cytoplasmic proteins and nuclear proteins in esophageal SCC cells. The immunoreactivity in T.Tn cells was confirmed by Western blot analysis as described in the Patients and Methods section.
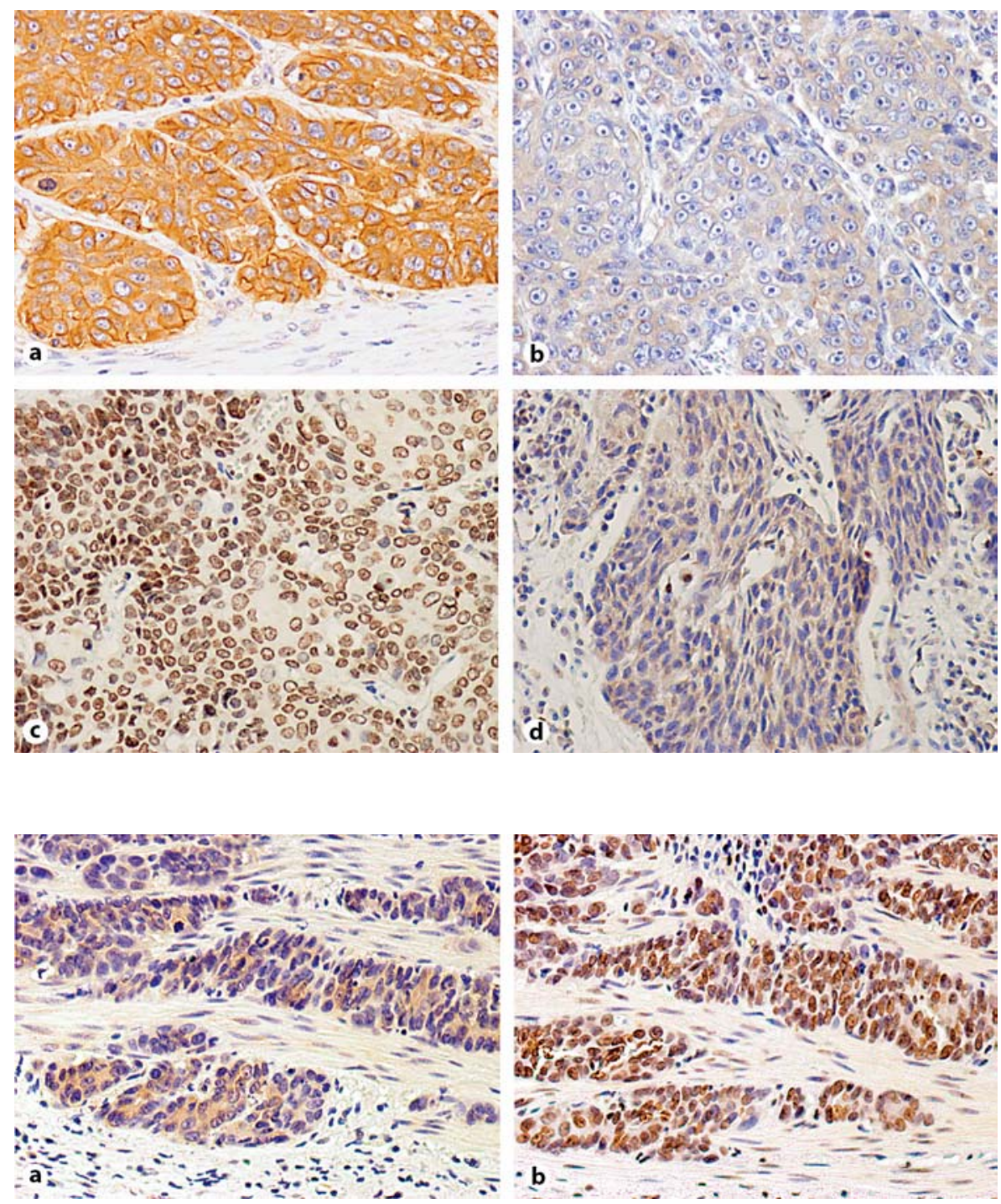

Fig. 3. Relationship between EGFR (a) and pEGFR (b) immunostaining patterns in esophageal SCC. a Nonmembrane-type pattern of EGFR immunostaining. $\mathbf{b}$ In the same area as that indicated in $\mathbf{a}$, the immunostaining pattern of pEGFR is of the nuclear type.

\section{Prognostic Value of EGFR and pEGFR Expression}

Patterns in Patients with Esophageal SCC

The log-rank test showed that disease stage and lymph node metastasis were significantly prognostic for overall patient survival ( $\mathrm{p}<0.0001$ and $\mathrm{p}=0.0005$, respectively). In contrast, none of the clinicopathological parameters, including age, gender, histology, lymphatic invasion or venous invasion, were significantly prognostic for overall survival.
To evaluate the prognostic significance of EGFR and pEGFR immunostaining patterns, Kaplan-Meier curves were constructed (fig. 4). We found that patients whose esophageal SCCs showed a membrane-type EGFR immunostaining pattern tended to have a good outcome (fig. 4a). With regard to the relationship between prognosis and pEGFR immunostaining pattern, patients with a nuclear pattern had a significantly worse outcome than those with a nonnuclear pattern (fig. $4 \mathrm{~b}$ ). 
We next examined whether staging and pEGFR expression pattern were independent for predicting overall survival. Multivariate Cox regression analysis revealed that staging was significantly predictive for overall survival ( $\mathrm{p}=0.006$, hazard ratio $=5.56,95 \%$ confidence interval 1.64-18.87), whereas pEGFR expression pattern was not statistically significant $(\mathrm{p}=0.162$, hazard ratio $=$ $2.29,95 \%$ confidence interval $0.72-7.30$ ).

\section{Discussion}

In the present study, we confirmed that esophageal SCC cells show 2 distinct immunostaining patterns, not only for EGFR but also for pEGFR: a membrane- or nonmembrane-type pattern, and a nuclear- or nonnucleartype pattern, respectively. Since EGFR is a transmembrane protein, it was originally believed that its expression would be detectable at the plasma membrane and in the cytoplasm, or that nuclear EGFR expression would be detected nonspecifically by immunohistochemistry. However, recent studies have suggested that EGFR may translocate from the plasma membrane to the nucleus [12], and moreover that translocated EGFR may function as a transcriptional regulator for oncogenic cyclin D1 or $\mathrm{B}-\mathrm{Myb}$, and subsequently play a role in tumorigenesis $[12$, 18]. Thus, an evaluation of immunoreactive localization for EGFR might yield some useful information on the association between the malignant potential and EGFR expression of tumors. Indeed, in the present study, we showed that diffuse cytoplasmic expression of EGFR, in parallel with the disappearance of its expression at the plasma membrane, was significantly prognostic for overall survival in patients with esophageal SCC.

In the present study we examined the expression not only of EGFR but also pEGFR, because pEGFR is the active form of EGFR and its intracellular translocation may reflect biological changes in tumors more clearly than conventional EGFR. Interestingly, nuclear translocation of pEGFR was significantly related not only to tumor stage but also lymph node metastasis, and moreover was a significantly better predictor of poor outcome than nonmembrane-type EGFR immunostaining in patients with esophageal SCC. Since the number of patients examined was relatively small, these findings will need to be verified by larger-scale studies. However, our data clearly suggest that nuclear translocation of pEGFR is associated with the malignant potential of esophageal SCC.

There are a number of commercially available antibodies against EGFR, and the selection of the most ap-

Localization of pEGFR in Esophageal

Squamous Cell Carcinoma

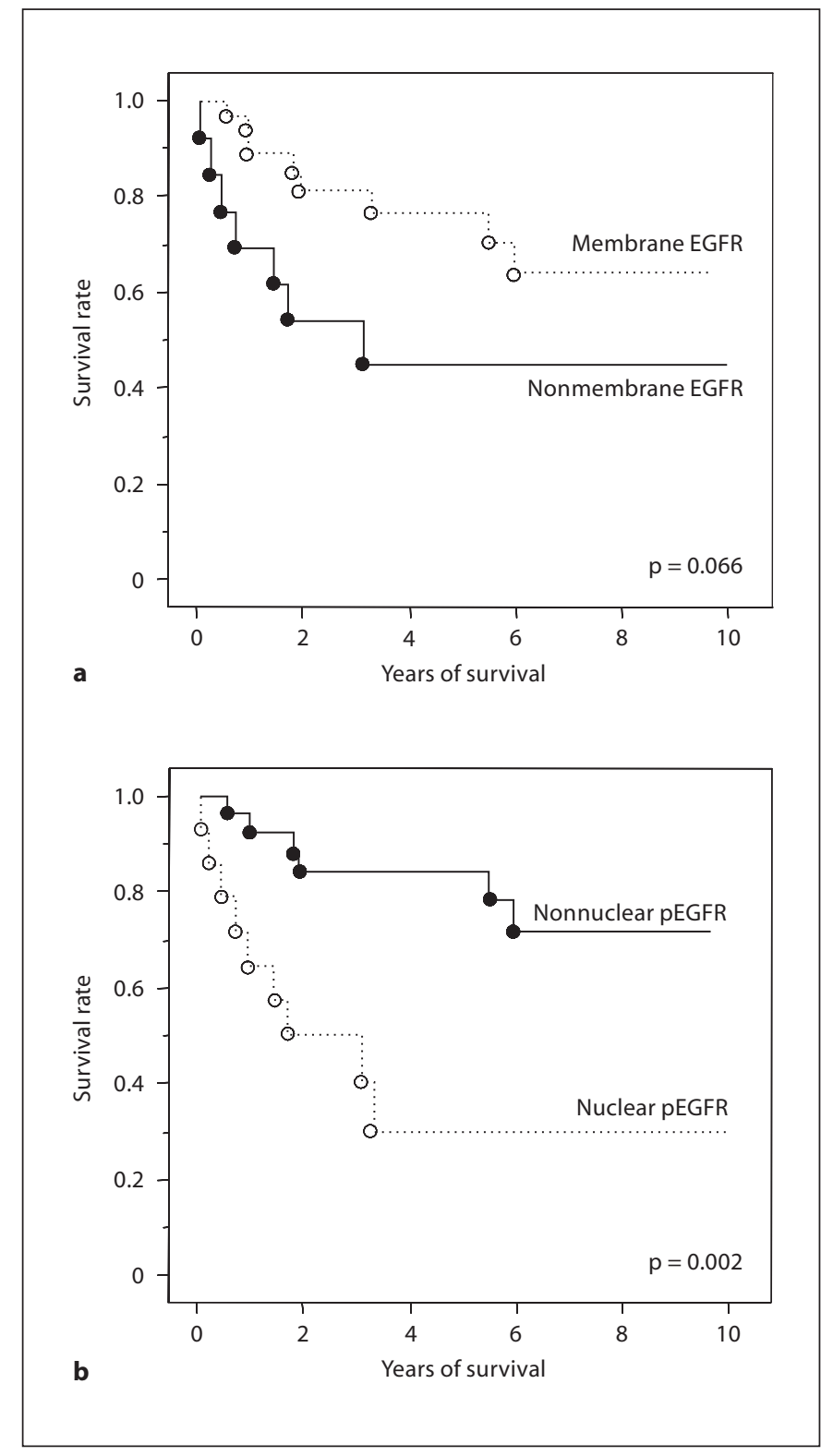

Fig. 4. Overall survival according to $\operatorname{EGFR}$ (a) and pEGFR (b) expression patterns in patients with esophageal SCC $(n=44)$. Kaplan-Meier curves were constructed and pairwise differences were analyzed by log-rank test.

Table 2. Relationship between EGFR and pEGFR immunostaining patterns in esophageal SCC

\begin{tabular}{llrrr}
\hline & & pEGFR & & p value \\
\cline { 3 - 4 } & & nuclear & nonnuclear & \\
\hline EGFR & $\begin{array}{l}\text { membrane } \\
\text { nonmembrane }\end{array}$ & 8 & 29 & 0.0005 \\
& 11 & 4 & \\
\hline
\end{tabular}


propriate one is important for examining the pathophysiological significance of EGFR expression in human diseases. In this study, we utilized a pEGFR (Tyr845) antibody because Tyr845 phosphorylation in the activation loop of the EGFR kinase domain is considered to participate in the general regulation of its function by maintaining enzymatic activity [19-21]. Regarding the mechanism of translocation of the EGFR family, it is considered that the intracellular or transmembrane domain may be transported by importins [22, 23]. Recently, Lo et al. [24] have examined the immunostaining of breast cancer samples by various kinds of anti-EGFR antibody and shown that such antibodies recognizing the intracellular domain can detect the signal not only at the plasma membrane but also in the cytoplasm and nucleus, whereas those recognizing the extracellular domain detect the membrane signal alone. Indeed, both the anti-EGFR and antipEGFR antibodies used in this study were raised against the intracellular domain of EGFR, and therefore the signals of both antibodies might be detected not only at the plasma membrane but also in the cytoplasm or nucleus, although the dominant signal localization may be changed by the biological condition of the tumor cells. Interestingly, in the present study, SCC showing nuclear immunostaining of pEGFR mostly showed a nonmembrane-type EGFR immunostaining pattern. This finding suggests that the EGFR activated by phosphorylation is actively translocated to the nucleus in such SCC cells. Importantly, however, patients with this type of SCC had a significantly poor outcome. Accordingly, although the molecular mechanism involved still remains unclear, nuclear translocation of pEGFR may be closely associated with higher malignancy of esophageal SCC.

In summary, we have observed that EGFR is detectable not only at the plasma membrane but also in the cytoplasm or nucleus of esophageal SCC cells, and moreover that the nuclear translocation of pEGFR is closely associated with poor prognosis of patients with esophageal SCC. Recently, many other cell surface receptors, not only for growth factors but also cytokines, have been reported to be detectable in the nucleus of tumor cells [2530]. Taken together, the data suggest that nuclear translocation of pEGFR plays an important role in tumor cell biology, and therefore the pathological significance of this phenomenon needs to be investigated in future studies.

\section{Acknowledgements}

The authors thank Chiaki Matsuyama, Ayako Shimizu, Takako Otsuki, Midori Katayama, Atsuko Kikuchi and Sachiko Miyahara (Department of Surgical and Molecular Pathology, Dokkyo University of Medicine, Tochigi, Japan) for their excellent technical and secretarial assistance.

\section{References}

1 Cohen S, Ushiro H, Stoscheck C, Chinkers M: A native 170,000 epidermal growth factor receptor-kinase complex from shed plasma membrane vesicles. J Biol Chem 1982;257: 1523-1531.

-2 Lo HW, Hsu SC, Hung MC: EGFR signaling pathway in breast cancers: from traditional signal transduction to direct nuclear translocalization. Breast Cancer Res Treat 2006; 95:211-218.

-3 Lo HW, Hung MC: Nuclear EGFR signaling network in cancers: linking EGFR pathway to cell cycle progression, nitric oxide pathway and patient survival. Br J Cancer 2006; 94:184-188.

4 Ritter CA, Arteaga CL: The epidermal growth factor receptor-tyrosine kinase: a promising therapeutic target in solid tumors. Semin Oncol 2003;30:3-11.

5 Klapper LN, Kirschbaum MH, Sela M, Yarden Y: Biochemical and clinical implications of the ErbB/HER signaling network of growth factor receptors. Adv Cancer Res 2000;77:25-79.
6 Woodburn JR: The epidermal growth factor receptor and its inhibition in cancer therapy. Pharmacol Ther 1999;82:241-250.

7 Nicholson RI, Gee JMW, Harper ME: EGFR and cancer prognosis. Eur J Cancer 2001;37: S9-S15.

8 Ang KK, Berkey BA, Tu X, Zhang HZ, Katz R, Hammond EH, Fu KK, Milas L: Impact of epidermal growth factor receptor expression on survival and pattern of relapse in patients with advanced head and neck carcinoma. Cancer Res 2002;62:7350-7356.

-9 Tsuchiya A, Katagata N, Kimijima I, Abe R: Immunohistochemical overexpression of CerB-2 in the prognosis of breast cancer. Surg Today 1993;23:885-890.

10 Spano JP, Lagorce C, Atlan D, Milano G, Domont J, Benamouzig R, Attar A, Benichou J, Martin A, Morere JF, Raphael M, PenaultLlorca F, Breau JL, Fagard R, Khayat D, Wind P: Impact of EGFR expression on colorectal cancer patient prognosis and survival. Ann Oncol 2005; 16:102-108.
Tokunaga A, Onda M, Okuda T, Teramoto T, Fujita I, Mizutani T, Kiyama T, et al: Clinical significance of epidermal growth factor (EGF), EGF receptor, and C-erB-2 in human gastric cancer. Cancer 1995;75:S1418S1425.

12 Lin SY, Makino K, Xia W, Matin A, Wen Y, Kwong KY, Bourguignon L, Hung MC: Nuclear localization of EGF receptor and its potential new role as a transcription factor. Nat Cell Biol 2001;3:802-808.

13 Wittekind C, Greene FL, Hutter RV, Klimpfinger M, Sobin LH: TNM Atlas: Illustrated Guide to the TNM Classification of Malignant Tumours, ed 5. New York, Springer, 2004, pp 74-83.

14 Fujita M, Fukui H, Kusaka T, Morita K, Fujii S, Ueda Y, Chiba T, Sakamoro C, Kawamata H, Fujimori T: Relationship between cyclooxygenase- 2 expression and K-ras gene mutation in colorectal adenomas. J Gastroenterol Hepatol 2000;15:1277-1281. 
- 15 Kawamata H, Furihata T, Omotehara F, Sakai T, Horiuchi H, Shinagawa Y, Imura J, Ohkura Y, Tachibana M, Kubota K, Terano A, Fujimori T: Identification of genes differentially expressed in a newly isolated human metastasizing esophageal cancer cell line, T.Tn-AT1, by cDNA microarray. Cancer Sci 2003;94:699-706.

$>16$ Jobin C, Haskill S, Mayer L, Panja A, Sartor RB: Evidence for altered regulation of I $\kappa \mathrm{B} \alpha$ degradation in human colonic epithelial cells. J Immunol 1997;158:226-234.

- 17 Sekikawa A, Fukui H, Fujii S, Takeda J, Nanakin A, Hisatsune H, Seno H, Takasawa S, Okamoto H, Fujimori T, Chiba T: REG Ia protein may function as a trophic and/or anti-apoptotic factor in the development of gastric cancer. Gastroenterology 2005;128: 642-653.

>18 Hanada N, Lo HW, Day CP, Pan Y, Nakajima Y, Hung MC: Co-regulation of B-Myb expression by E2F1 and EGF receptor. Mol Carcinog 2006;45:10-17.

-19 Biscardi JS, Maa MC, Tice DA, Cox ME, Leu TH, Parsons SJ: S-Src-mediated phosphorylation of the epidermal growth factor receptor on Tyr845 and Tyr1101 is associated with modulation of receptor function. J Biol Chem 1999;274:8335-8343.
20 Cooper JA, Howel B: The when and how of Src reguration. Cell 1993;73:1051-1054.

21 Hubbard SR, Wei L, Ellis L, Hendrickson WA: Crystal structure of the tyrosine kinase domain of the human insulin receptor. $\mathrm{Na}$ ture 1994;372:746-775.

22 Dittmann K, Mayer C, Fehrenbacher B, Schaller M, Raju U, Milas L, Chen DJ, Kehlbach R, Rodemann HP: Radiation-induced epidermal growth factor receptor nuclear import is linked to activation of DNA-dependent protein kinase. J Biol Chem 2005; 280:31182-31189.

23 Lo HW, Ali-Seyed M, Wu Y, Bartholomeusz G, Hsu SC, Hung MC: Nuclear-cytoplasmic transport of EGFR involves receptor endocytosis, importin betal and CRM1. J Cell Biochem 2006;98:1570-1583.

24 Lo HW, Xia W, Wei Y, Ali-Seyed M, Huang SF, Hung MC: Novel prognostic value of nuclear EGF receptor in breast cancer. Cancer Res 2005;65:338-348.

25 Curtis BM, Widmer MB, deRoos P, Qwarnstrom EE: IL-1 and its receptor are translocated to the nucleus. J Immunol 1990;144: 1295-1303.
26 Jans DA, Hassan G: Nuclear targeting by growth factors, cytokines, and their receptors: a role in signaling? Bioessays 1998;20: 400-411.

27 Pillai G, CookN, Turley H, Leek RD, Blasquez C, Pezzella F, Harris AL, Gatter KC: The expression and cellular localization of phosphorylated VEGFR2 in lymphoma and nonneoplastic lymphadenopathy: an immunohistochemical study. Histopathology 2005; 46:209-216.

28 Rakowicz-Szulczynska EM, Herlyn M, Koprowski $\mathrm{H}$ : Nerve growth factor receptors in chromatin of melanoma cells, proliferation melanocytes, and colorectal carcinoma cells in vitro. Cancer Res 1988;48:7200-7206.

29 Maher PA: Nuclear translocation of fibroblast growth factor (FGF) receptors in response to FGF-2. J Cell Biol 1996;134:529536.

30 Zwaagstra JC, Guimond A, O’Connor-McCourt MD: Predominant intracellular localization of the type 1 transforming growth factor- $\beta$ receptor and increased nuclear accumulation after growth arrest. Exp Cell Res 2000;258:121-134. 